\title{
Light contamination in stable isotope-labelled internal peptide standards is frequent and a potential source of false discovery and quantitation error in proteomics
}

\author{
Mogjiborahman Salek $^{1,2}$ (D) . Jonas D. Förster ${ }^{1,2,3}$ (D) . Wolf-Dieter Lehmann ${ }^{4} \cdot$ Angelika B. Riemer $^{1,2}$ (D)
}

Received: 8 November 2021 / Revised: 22 December 2021 / Accepted: 26 January 2022 / Published online: 4 February 2022

(c) The Author(s) 2022

\begin{abstract}
In mass spectrometry-based proteomics, heavy internal standards are used to validate target peptide detections and to calibrate peptide quantitation. Here, we report light contamination present in heavy labelled synthetic peptides of high isotopic enrichment. Application of such peptides as assay-internal standards potentially compromises the detection and quantitation especially of low abundant cellular peptides. Therefore, it is important to adopt guidelines to prevent false-positive identifications of endogenous light peptides as well as errors in their quantitation from biological samples.
\end{abstract}

Keywords Mass spectrometry $\cdot$ Proteomics $\cdot$ Immunopeptidomics $\cdot$ Internal standards $\cdot$ Stable isotope-labelled (SIL) peptides

\section{Introduction}

Stable isotope labelling (SIL) of amino acids in general starts by growing microorganisms (e.g. green algae and cyanobacteria) in the presence of highly ${ }^{13} \mathrm{C}$-enriched $\mathrm{CO}_{2}$ and/or highly ${ }^{15} \mathrm{~N}$-enriched ammonia (each at $>99.5$ atom \% enrichment) as sole source of carbon and nitrogen, respectively $[1,2]$. Labelled amino acids obtained in this way are then incorporated into peptides either by chemical

Mogjiborahman Salek and Jonas D. Förster contributed equally to this work.

Mogjiborahman Salek

m.salek@dkfz.de

$\triangle$ Angelika B. Riemer

a.riemer@dkfz.de

1 Immunotherapy \& Immunoprevention, German Cancer Research Center (DKFZ), Im Neuenheimer Feld 280, 69120 Heidelberg, Germany

2 Molecular Vaccine Design, German Center for Infection Research (DZIF), Partner Site Heidelberg, Heidelberg, Germany

3 Faculty of Biosciences, Heidelberg University, Heidelberg, Germany

4 Molecular Structure Analysis, German Cancer Research Center (DKFZ), Im Neuenheimer Feld 280, 69120 Heidelberg, Germany synthesis or metabolic labelling [3]. Peptides containing at least one amino acid highly enriched in ${ }^{13} \mathrm{C}$ and $/$ or ${ }^{15} \mathrm{~N}$ are often named "heavy" to set them off against their cognates with natural isotopic abundances, named "light" in this context.

In targeted mass spectrometry (MS)-based proteomics and in particular peptidomics studies, heavy internal standards are regarded as the current gold standard to validate peptide detection and quantitation. For example, with peptides presented by human leukocyte antigen (HLA) class I molecules, this identification is directly linked to subsequent immunotherapy and anti-cancer vaccine design [4-6]. The challenge in achieving accurate quantitation is to effectively enhance precision and minimize bias due to various instrumental parameters or matrix effects. Isotope dilution MS (IDMS) based on heavy internal standards fits this purpose and provides proof of detection and absolute quantitation of the highest precision and accuracy fit for clinical validation [7-9]. More recently, internal standards were used to dynamically control signal acquisition for endogenous light peptides via live instrument control [10]. With these broad applications in the field of mass spectrometry and in particular those assays aiming at clinical translation, high isotopic purity of heavy peptides used as internal reference is of key importance.

However, we here report that heavy peptides generated by chemical synthesis frequently contain sufficient levels 
of light cognates to bias interpretation of MS data, thus wrongly validating the detection of cellular peptides.

\section{Materials and methods}

\section{Synthetic peptides and sample preparation}

Peptide Retention Time Calibration (PRTC) Mixture $\left(88,321\right.$, Pierce $\left.^{\mathrm{TM}}\right)$ was purchased from Thermo Fisher Scientific and is prepared at the same quality standards as "AQUA Ultimate" grade peptides of high chemical purity (>99\%). Custom-synthetized heavy peptides were obtained from JPT Peptide Technologies (Berlin, Germany) and Synpeptide Co., Ltd (Shanghai, China) for low chemical purity $(>70 \%)$. The above vendors are indicated in Table S1 as vendors 1, 2 and 3, respectively, and coloured accordingly in Fig. 1. For all vendors, the isotope purity is reported $>99 \%$ isotopic enrichment, and incorporated heavy amino acids are $\mathrm{V}\left({ }^{13} \mathrm{C}_{5},{ }^{15} \mathrm{~N}_{1}\right)$, L/I $\left({ }^{13} \mathrm{C}_{6},{ }^{15} \mathrm{~N}_{1}\right), \mathrm{K}$ $\left({ }^{13} \mathrm{C}_{6},{ }^{15} \mathrm{~N}_{2}\right)$ and $\mathrm{R}\left({ }^{13} \mathrm{C}_{6},{ }^{15} \mathrm{~N}_{4}\right)$. Upon arrival, peptides were dissolved in DMSO at $0.5 \mathrm{nmol} / \mu \mathrm{L}$, brought to a final concentration of $5 \mathrm{pmol} / \mu \mathrm{L}$, dried and stored at $-80{ }^{\circ} \mathrm{C}$ until LC-MS analysis.

\section{Immunoprecipitation of HLA-displayed peptides}

HLA immunoprecipitation (IP) was performed according to previously published protocols $[11,12]$. Briefly, $1 \times 10^{8}$ C33A cells, a HPV-negative cervical cancer cell line, were lysed with a lysis buffer containing $1 \% \mathrm{~N}$-octyl- $\beta-\mathrm{D}$ glucopyranoside, $0.25 \%$ Na-deoxycholate and protease inhibitor cocktail (Sigma-Aldrich, Mannheim, Germany)/ PMSF (Carl Roth, Karlsruhe, Germany) in PBS. After centrifugation at $40,000 \times g, 4{ }^{\circ} \mathrm{C}$, for $30 \mathrm{~min}$, HLApeptide complexes were immuno-isolated by incubation with BB7.2 mouse anti-human HLA-A2 monoclonal antibody crosslinked to protein $\mathrm{G}$ Sepharose beads (Cytiva, Marlborough, MA, USA) for $4 \mathrm{~h}$ at $4{ }^{\circ} \mathrm{C}$ under constant mixing on a rotating wheel. Supernatant was discarded after centrifugation at $3200 \times g$, for $3 \mathrm{~min}$ at RT. Pelleted HLA-peptide complexes bound to antibody-beads were washed 3 times in each of the following steps: first with ice-cold $20 \mathrm{mM}$ Tris- $\mathrm{HCl} \mathrm{pH} 8$ containing $150 \mathrm{mM}$ $\mathrm{NaCl}$, followed by the same buffer but with $400 \mathrm{mM}$ $\mathrm{NaCl}$, and finally with $20 \mathrm{mM}$ Tris- $\mathrm{HCl}$ alone. Peptides were eluted from HLA bound to antibody-beads by $0.3 \%$ TFA. Resulting peptides were desalted by reverse-phase purification using a SepPak 96-well plate and dried by vacuum centrifugation (Concentrator plus, Eppendorf, Hamburg, Germany).

\section{LC-MS}

Samples were dissolved in 5\% ACN, $0.1 \%$ TFA. Synthetic peptides were injected up to $280 \mathrm{fmol}$ per peptide on column. All samples were analysed by liquid chromatography (U-3000, Thermo Fisher Scientific) coupled to Q Exactive HFX or Orbitrap Exploris 480 (Thermo Fisher Scientific). The LC gradient consisted of a first segment increasing from 3 to $7.5 \% \mathrm{~B}\left(19.9 \% \mathrm{H}_{2} \mathrm{O}\right.$, $0.1 \% \mathrm{FA}, 80 \% \mathrm{ACN})$ and $92.5 \% \mathrm{~A}\left(0.1 \% \mathrm{FA}\right.$ in $\left.\mathrm{H}_{2} \mathrm{O}\right)$ over $5 \mathrm{~min}$, followed by a second segment reaching $35.6 \% \mathrm{~B}$ in 75 min. Finally, the \% B was increased in 2 steps to $95 \%$ in 4 min, followed by 5 min wash before 11 min equilibration at $2 \%$ B. For acquiring precursor isotopic envelopes, Orbitrap Exploris was operated with multiplexed tSIM scans for simultaneous mass measurement of multiple peptide precursor ions using $240 \mathrm{k}$ resolution at $200 \mathrm{~m} / \mathrm{z}$, $100 \mathrm{~ms}$ injection time (IT), $100 \%$ AGC target and 2-3 separate quadrupole isolation windows, focused on the heavy and the light precursors. Protonated polycyclodimethylsiloxane (PCM-6, a background ion originating from ambient air) at $445.12 \mathrm{~m} / \mathrm{z}$ served as a lock mass. MS2 data was acquired with PRM scans using $60 \mathrm{k}$ resolution at $200 \mathrm{~m} / \mathrm{z}$ with a narrow $<1 \mathrm{~m} / \mathrm{z}$ isolation window tuned per precursor. Settings for the detection of heavy precursors were $30 \mathrm{~ms}$ IT, 50\% AGC target. For light precursors, they were $1000 \mathrm{~ms}$ IT, $1000 \%$ AGC target. These settings are identical to those we use for the analysis of endogenous peptides in a biological sample.

To test the matrix effect, either 10 or $40 \mathrm{ng} \mathrm{HeLa}$ Protein Digest Standard (Pierce ${ }^{\mathrm{TM}}$, Thermo Scientific ${ }^{\mathrm{TM}}$ ) served as a test matrix which were spiked with $150 \mathrm{fmol}$ (Fig. 2a) or $100 \mathrm{fmol}$ (Fig. 2b,c) of heavy target peptides. As a control, an IP sample obtained as described above was spiked with $50 \mathrm{fmol}$ heavy target peptides (Fig. 2d). MS2 data was acquired with PRM scans using $60 \mathrm{k}$ resolution at $200 \mathrm{~m} / \mathrm{z}$ with a narrow $<1 \mathrm{~m} / \mathrm{z}$ isolation window tuned per precursor. To mirror the conditions of analysis of a real biological sample, the IP sample from C33A cells spiked with heavy peptides was analysed with parameters for heavy and light precursor mass measurements at $150 \mathrm{~ms}$ IT and 100\% AGC target for the former, $1000 \mathrm{~ms}$ and $1000 \%$ for the latter. To explore the impact of the matrix effect on the sensitivity of peptide detection, MassPREPTM $E$. coli digestion standard (MPDS E. coli, Water, Milford, MA, USA) was used in the specified amounts to test the 
detection of the peptides from vendors 1 and 2 (Fig. $2 \mathrm{e}-\mathrm{g}$, Table S1). This data was acquired on a Q Exactive HF-X with an MS scan followed by 8 PRM scans, each with $0.7 \mathrm{~m} / z$ isolation window for a maximum of $350 \mathrm{~ms}$ IT and $5 \mathrm{e} 5$ ions AGC target with $23 \%$ normalized collision energy (NCE).

\section{Data analysis}

MS1 data analysis was performed with R (v. 4.1) [13] with the "tidyverse" suite of packages (v. 1.3.0) [14]. Theoretical isotopic envelopes were calculated with the IsoSpec R package (v. 2.1.3) [15]. For theoretical heavy envelopes, several isotopic purity settings for heavy isotopes ${ }^{13} \mathrm{C}$ and ${ }^{15} \mathrm{~N}$ were probed and $97 \%$ isotopic purity was selected for best fits. Theoretical isotopic envelopes and TSIM spectra were centroided and matched with $4 \mathrm{ppm}$ mass tolerance. The matched envelope was then fitted with a linear model, minimizing the sum of squares error.

MS2 data was analysed with the Skyline software (v. 20.2) [16]. Top 4 intensity product ions were extracted with $10 \mathrm{ppm}$ mass tolerance. Detected peaks were manually curated. Light peaks were discarded when peak retention times or shapes did not match with the heavy reference, when the normalized spectral contrast angle (dotp) [17] was low, or when too few transitions were detected. For the complex peptide matrix (CPM) analysis, the "nls.multstart" (v. 1.2.0) R package [18] was used to fit the response of the peptide MS2 intensity $(I)$ to the CPM load with the function $I=a([C P M]-b)^{10^{\wedge} c}$.

\section{Results and discussion}

The sequences and extent of light contamination in the synthetic heavy peptides we tested are given in full in supplementary Table S1 and Figure S1. For these assays, MS settings were tuned for maximum sensitivity to allow for detection of contaminating light cognates at intensities several orders of magnitude below those of the corresponding heavy precursors. Accordingly, the aim was not the absolute quantitation of the light contamination but measuring the relative scale of the phenomenon. Therefore, we calculated for each peptide the intensity ratio of light to heavy signals, given as parts per million (ppm) or percent. The different sets of peptides reported here were in use at the time in our laboratory and reflect different suppliers and purities. They include 9-15 amino acids long HLA binders or tryptic peptides containing 1 or 2 labelled residues.

Representative for the peptides of highest available quality $(99.5 \%$ isotope purity, $>97 \%$ chemical purity, concentration precision $\pm 10 \%$, absolute quantitation (AQUA) grade), peptide \#43 GISNEGQNASIK, shows precursor isotopic envelopes at both light (monoisotopic 0 ) and heavy (monoisotopic + 8) $\mathrm{m} / \mathrm{z}$ (Fig. 1a). The strong similarity of the fragmentation patterns between the light and heavy monoisotopic precursor ions in comparison to an external library, as captured by high spectral contrast angle (dotp) values $(0.96,0.98)$, confirms the sequence identity of the light and heavy peptides (Fig. 1b). The correct peptide identification is further supported by the alignment of their retention times, indicating virtually perfect chromatographic co-elution. The light contamination of peptide \#43 GISNEGQNASIK is measured as $219 \mathrm{ppm}$ according to the MS2 peak area of the shown transitions (Fig. 1c and Figure S1, for other peptides from this set: \#40 (4507 ppm) to \#54 (25 ppm)).

Although sources of such contamination can be multiple, the absence of a gradual increase in the intensity of intermediate signals between the light $(0)$ and heavy $(+8)$ monoisotopic peaks excludes the possibility of incomplete incorporation of ${ }^{13} \mathrm{C}$ and ${ }^{15} \mathrm{~N}$ isotopes during the initial metabolic labelling of the amino acids. More likely, the source of contamination would therefore be the introduction of completely unlabelled, i.e. "light", amino acids from an external source during amino acid labelling, extraction or peptide synthesis.

In around $50 \%$ of all heavy synthetic peptides we analysed as mixtures within separate batches from different vendors, the level of light contamination was higher than $100 \mathrm{ppm}(0.01 \%$, Fig. 1c). The highest level of contamination measured was $4.5 \%$ for peptide \#40 TASEFDSAIAQDK belonging to the AQUA grade peptide mixture (Fig. 1c and Table S1). Initial measurements indicated exceedingly high contamination of $>900 \mathrm{ppm}$ for a total of 6 peptides. When confirming these peptides individually, the contamination assessment could be corrected down by factors of 100 to 1500 for those peptides, where the source of contamination was tracked down to another peptide of related sequence in the same mixture (Table S1, peptides \#92, \#95, \#99, \#100,\#113). For instance, the peptide \#92 RALYVDSLFF initially showed contamination of $32,812 \mathrm{ppm}$ but could be corrected down to $84 \mathrm{ppm}$ when measured separately, whereas the source of major contamination was determined to be the peptide \#84 RALYVDSLFFL which introduced RALYVDSLFF as incomplete synthesis product. Thus, spike-in 
a

Number of Heavy Isotopes

$0+1+2+3+4+5+6+7+8+9+10+11$
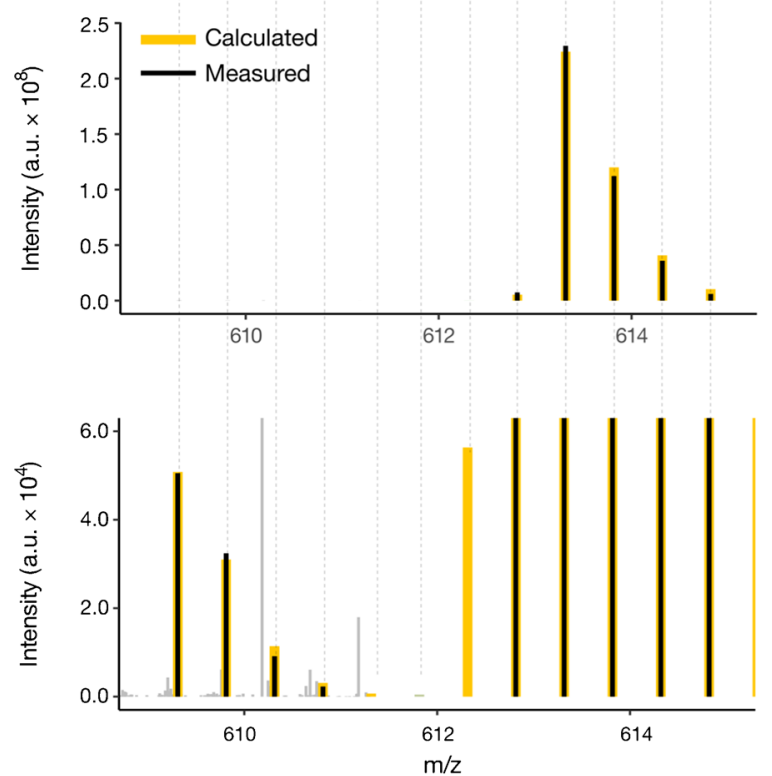

b

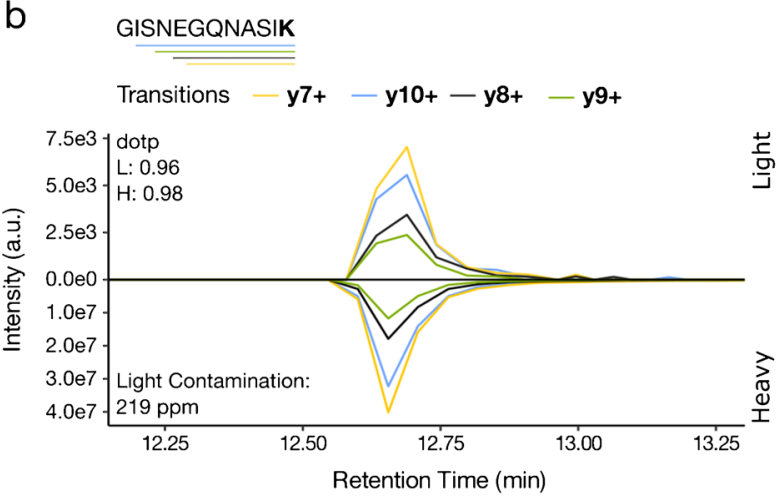

Fig. 1 Presence of light contamination in heavy peptides. a Upper and lower panels show selected ion monitoring (SIM) data acquisition scans for the light and heavy forms of a representative peptide and its $4000 \times$ zoom in, respectively. The calculated (yellow) and experimentally measured (black) isotope patterns of the labelled peptide and its light contamination are displayed. The indicated number of heavy isotopes, " 0 " and " +8 ," corresponds to the light and heavy monoisotopic signals, respectively. Background peaks not matched to the isotope pattern are displayed in grey. b Extracted fragmention chromatograms representing the light and heavy forms of the depicted peptide sequence (the labelled residue, lysine (K), is in bold, for which the sum of incorporated stable isotopes is $8\left({ }^{13} \mathrm{C}_{6}\right.$ and $\left.{ }^{15} \mathrm{~N}_{2}\right)$, as indicated in a). The bars underneath the peptide sequence corre-

of such related sequences in a biological sample would be problematic. Nevertheless, it is important to note that the light contamination reported here cannot be attributed solely to cross-contamination due to mixing of peptides of low chemical purity. The separate analysis of single
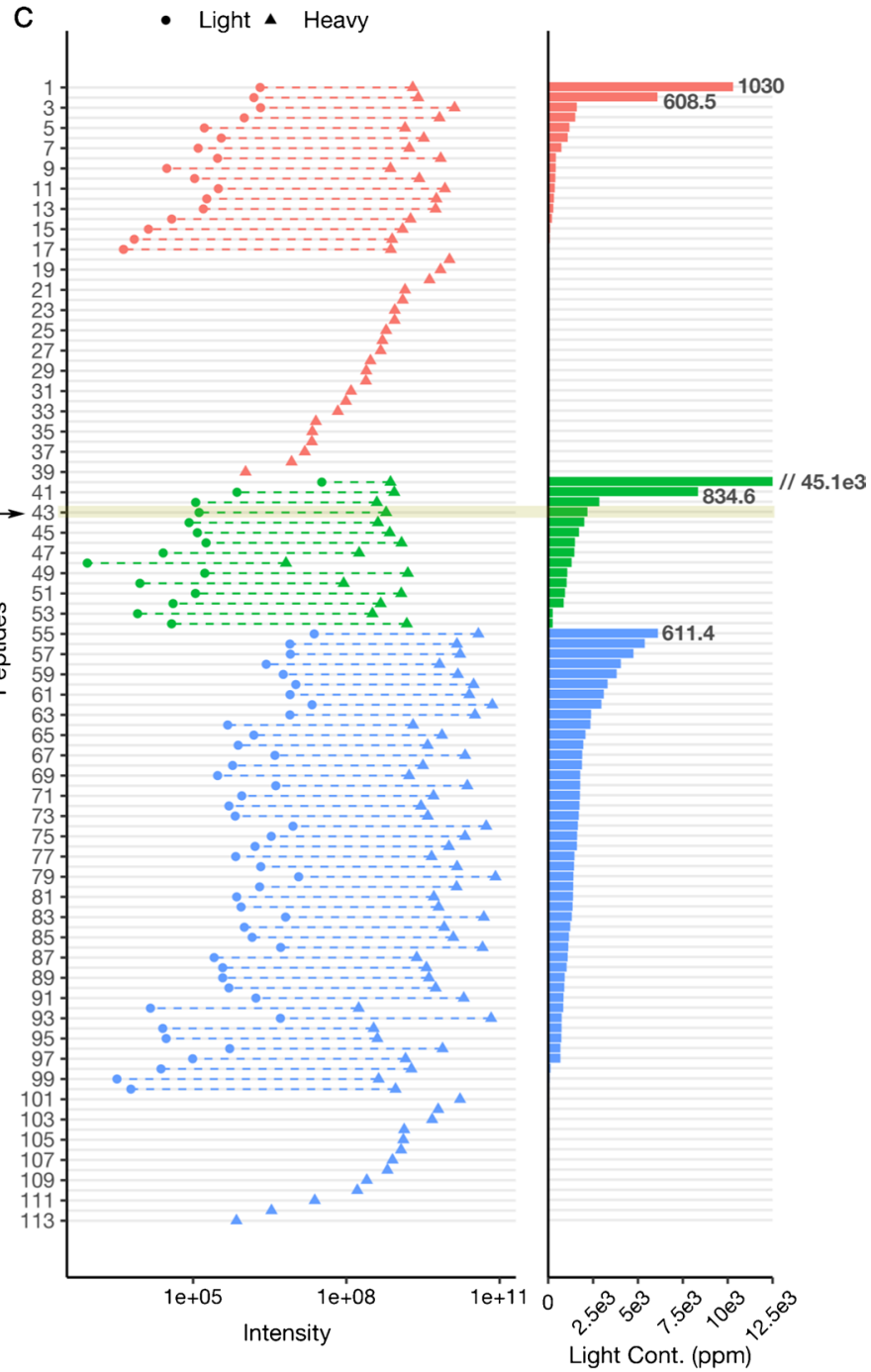

spond to the detected fragments or transitions and are colour-coded accordingly. dotp is the normalized spectral contrast angle that is scoring the similarity of the detected peptide's fragmentation pattern of light $(\mathrm{L})$ and heavy $(\mathrm{H})$ precursors, compared to a reference library. The identity of the peptide is further confirmed by the co-elution of the light and heavy signals. c Extent of light contamination $(\mathrm{L} / \mathrm{H})$ for 113 tested heavy peptides, from three vendors (for colour scheme see Table S1). The light contamination for each peptide is shown in the left panel as the summed peak area for the top 4 fragments of the light (dots) and heavy (triangles) peptides. The right panel shows the extent of light contamination as parts per million (ppm). The arrow pinpoints the peptide \#43 (219 ppm), for which the details of light contamination are shown in panels $\mathbf{a}$ and $\mathbf{b}$

peptides still shows light contamination (Table S1, \#1 KLGEIVTTI). In addition, when analysing three independent batches of the AQUA grade peptides (chemical purity $>97 \%$ ), the contamination remained high (\#40: $4.5 \%, 1.1 \%$ or $0.04 \%$, data not shown). Further light 
signal of isobaric nature and similar spectral composition was in some cases observed for peptides containing the amino acids I or L (Figure S1: \#2, \#60, \#107). This seems to be in agreement with reports that isoleucine used in peptide synthesis can contain major impurities of leucine and vice versa [19]. In our experiments, a slight shift in retention time, compared to the heavy reference, in many cases seems to reveal where such a substitution took place.

Data acquisition with instrument parameters tailored for high sensitivity inevitably increases the chances of detecting light contaminations as low as 50 ppm (Fig. 2a, Table S1, \#8 RTLEDLLMGT). Similarly, in quantitative MS, the well-documented matrix effect [20-22], often attributed to the changes in the efficiency of electrospray ionization, can enhance or suppress a target peptide signal. Indeed, we observed that the analysis of heavy peptides in the presence of a CPM (here: HeLa tryptic digest, free of target peptide signal) enhances both the signal of the heavy peptide and of its light contamination, which might have remained undetected in the absence of the matrix (Fig. 2b). Increasing the amount of CPM showed similar effects as increasing instrument sensitivity of detection (Fig. 2c). It has been suggested that consistent quantitation requires analysis in a fixed amount of matrix [23], implying that in biological experiments, negative controls including heavy internal standards need to be performed in the presence of cellular or closely related matrices. In the absence of such a control, peptide detection in a biological sample would lack sufficient level of objective evidence to distinguish the light contamination introduced by the heavy internal standard, from a bona fide endogenous peptide (Fig. 2d).

To further investigate the observed CPM effect, we analysed 54 (Table S1, vendors 1 and 2) heavy peptides covering the entire chromatographic retention time range in the presence of increasing amounts of an unrelated matrix (E. coli tryptic digest free of SIL peptides). The summed intensities of the top 6 fragment ions for three representative peptides with early, intermediate and late retention times indicate that hydrophilic peptides, represented by peptide \#49 SAAGAFGPELSR, need much less CPM to reach their maximum intensity than hydrophobic peptides, represented by peptide \#48 LSSEAPALFQFDLK. Collectively, the response of the intensity $(I)$ for each of the 54 peptides to the amount of CPM is best captured by $I=a$ $([C P M]-b)^{10^{\wedge} c}$, where $c$ is representing the curvature as negative, null or positive, and $a$ and $b$ are scaling and offset factors, respectively. $c$ delineates three responsiveness behaviours to the amount of CPM, as fast, linear and slow (Fig. 2f). Indeed, this peptide-specific responsiveness correlates linearly with the chromatographic retention time of the peptides (Fig. 2g), suggesting that the MS signal enhancement by CPM in our data is mainly caused by preventing peptide losses via hydrophobic interactions to vessel surfaces.

The consequences of light contamination present in heavy internal standards are even more important for interpretation of LC-MS data in biological contexts, as modern MS instrumentations are sensitive by design. Newly developed sophisticated data acquisition approaches [10, 24-26] further increase the basic instrumental sensitivity and thereby the importance of taking into account the unappreciated source of error introduced by light contamination of heavy peptides. For instance, recently introduced intelligent instrument control improves IDMS by dynamic adjustment of detection parameters based on heavy internal standards. A low resolution survey of heavy standards added to the sample at a higher concentration will trigger real-time measurement of light endogenous peptides of low abundance at high resolution and sensitivity [10]. Here, light contamination, introduced by the addition of heavy labelled peptides of seemingly high isotopic purity, can be easily mistaken as endogenous light peptides leading to false-positive identifications. The resulting perturbation of the measured quantity can also lead to flawed quantitation of the endogenous light peptide.

We therefore recommend the adoption of a few simple and rational guidelines to prevent false-positive detection of endogenous peptides. First, the impact of light contamination in batch analyses with multiple peptides can be controlled by consistent design of the peptide labelling. For instance in the case of KSVLTAFLMLW and KSVLTAFLM, the first peptide contains an unlabelled segment identical to the second, which should be prevented by carefully selecting the site of labelling, and if necessary introducing a second labelling within the peptide sequence. Second, it is paramount to determine systematically that the employed LC-MS method does not produce any light target signal when performed with a suitable negative control matrix spiked with the heavy internal standard peptide of interest. Additionally, in targeted MS workflows, it is still common to use light synthetic peptides, physically indistinguishable from the endogenous targets, for the optimization of instrument parameters. We strongly recommend that the LC-MS system is not exposed to light synthetic target peptides under any circumstances, as carry-over could again lead to false-positive detection. 
a

RTLEDLLMGT++

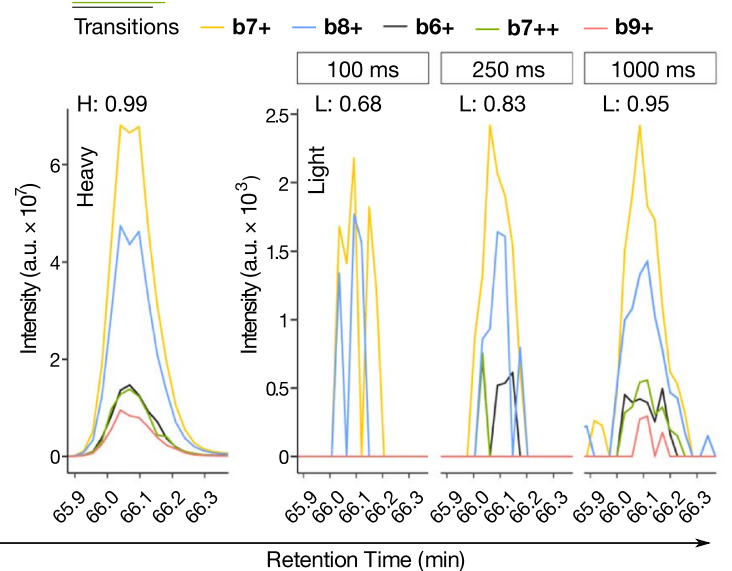

C

RTLEDLLMGT++

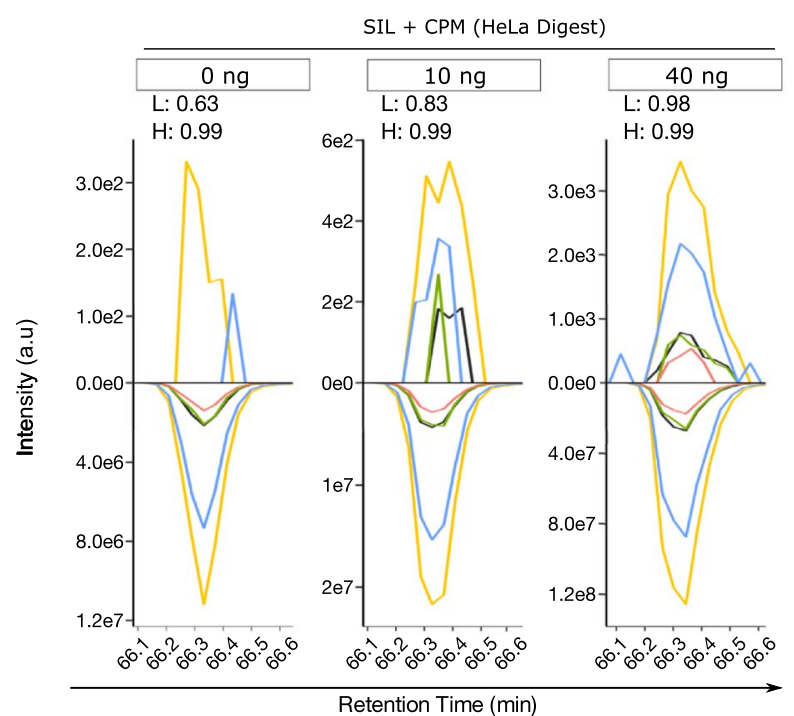

b

RTLEDLLMGT++

CPM (HeLa Digest) SIL CPM + SIL

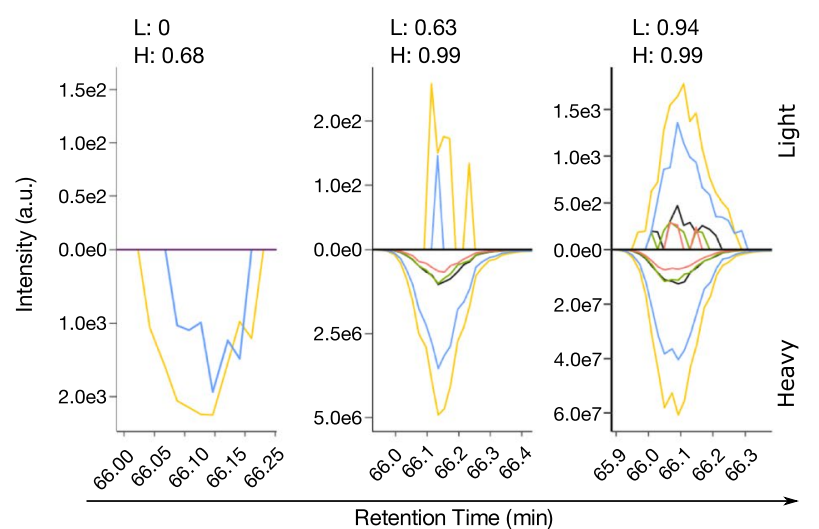

d

RTLEDLL(ox)MGT++

Transitions - b7+ - b8+ - b8++ - b7++

IP Sample SIL IP Sample + SIL

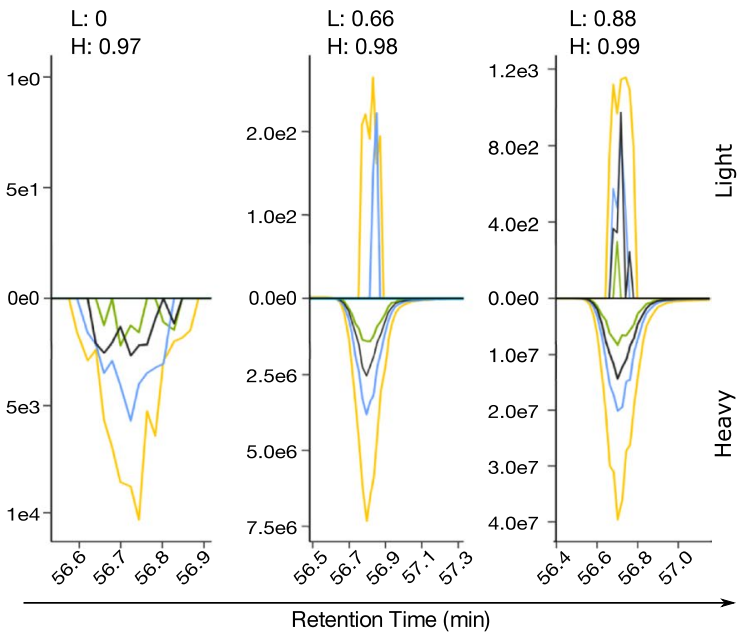

e

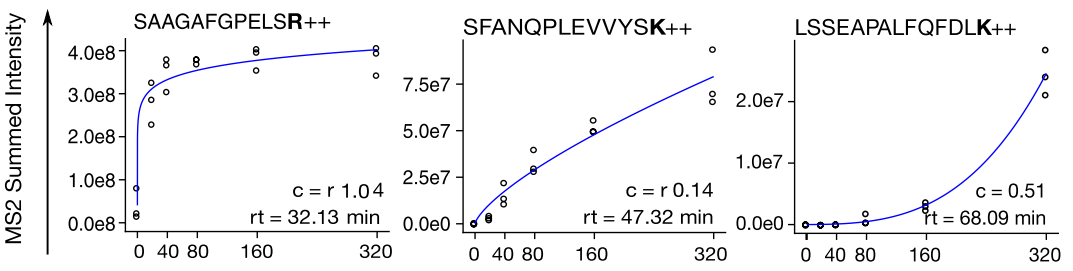

CPM (E. coli Digest [ng])

f

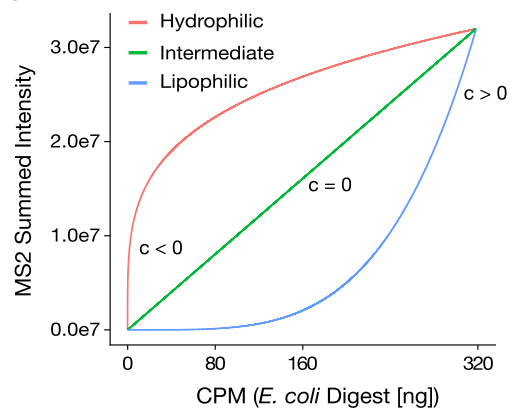

$\mathrm{g}$

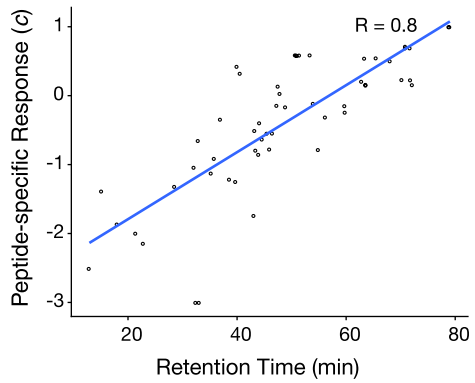


4 Fig. 2 Injection time and matrix effects on the detection of light contamination. a-d Extracted ion chromatograms representing the transitions (fragments) corresponding to the depicted heavy peptide sequence and its light contamination detected in different conditions. dotp comparison to reference library is annotated for light (L) and heavy $(\mathrm{H})$ signals. a Increasing of injection time (sensitivity); b presence or absence of a complex peptide matrix (CPM) (40 ng HeLa tryptic digest); $\mathbf{c}$ increasing amounts of CPM (0, 10, 40 ng HeLa tryptic digest); $\mathbf{d}$ in the context of anti-HLA immunoprecipitation (IP) sample. Oxidized peptide is targeted in this assay. Heavy reference signal in the IP sample is trace-level carry-over from other experiments on the same LC system. This is common for heavy peptides injected at relatively high concentrations. $\mathbf{e}-\mathbf{g}$ Correlation between the chemical nature of target peptides and the amount of CPM (0-320 ng E. coli tryptic digest). Three technical replicates per condition. The response of peptide intensity to CPM amount is fitted with $I=a([C P M]-b)^{10^{\wedge} c}$; e three representative peptides (hydrophilic, intermediate, lipophilic) for different behaviours in the presence of CPM. f The effect of factor $c$ and the modes that were commonly observed for peptides of different hydrophobicities. $\mathrm{g}$ The factor $c$ shows a linear correlation with peptide retention time (RT) (Pearson correlation coefficient of 0.8 )

\section{Conclusion}

We here report that heavy synthetic peptides produced with the highest chemical and isotope purity can still contain substantial amounts of light cognates. The data was initially presented at the HUPO 2019 conference and its HUPOHIPP satellite meeting in Adelaide [27]. To the best of our knowledge, this under-appreciated source of error is only described in one other publication, as one of several pitfalls that can obscure the analysis of HLA ligandome data [28]. We here provide an in-depth analysis of light contamination by (i) testing heavy peptides from multiple providers, (ii) measuring the overall extent of light contamination and (iii) describing the matrix effect that enhances the intensity of light contamination that otherwise may remain undetected in quality controls. Given the high sensitivity of modern mass spectrometers, light contamination of internal standards, even as low as $50 \mathrm{ppm}$, will inevitably lead to a high level of false discovery. In contrast to protein detection relying on multiple peptides, the impact of the neglected source of error reported here is expected to be large on the analysis of single peptides such as low abundance post-translational modifications in cellular signalling [29] and tumour-derived HLA-displayed peptides [5], often identified at the limit of detection. To prevent the generation of false-positive detections by such studies in the future, we recommend easy-toimplement protective measures.

Supplementary Information The online version contains supplementary material available at https://doi.org/10.1007/s00216-022-03931-w.

Acknowledgements The authors gratefully acknowledge Rebecca Köhler for excellent technical assistance and Dr. Jonas Becker for careful proofreading and editing of the manuscript.
Author contribution Conceptualization, methodology, data acquisition: MS and JDF. Formal bioinformatics analysis: JDF. Data interpretation: MS, JDF, WDL. Writing - original draft preparation: MS. Writing — review and editing: MS, JDF, WDL, ABR. Funding acquisition and resources: ABR. Supervision: MS and ABR.

A preprint version of this article is available on BioRxiv: https:// www.biorxiv.org/content/10.1101/2021.11.08.467684v1

Funding Open Access funding enabled and organized by Projekt DEAL. This work was funded through the German Cancer Research Center (DKFZ), the National Center for Tumor Diseases (NCT) Heidelberg and the German Center for Infectious Diseases (DZIF).

\section{Declarations}

Competing interests The authors declare no competing interests.

Open Access This article is licensed under a Creative Commons Attribution 4.0 International License, which permits use, sharing, adaptation, distribution and reproduction in any medium or format, as long as you give appropriate credit to the original author(s) and the source, provide a link to the Creative Commons licence, and indicate if changes were made. The images or other third party material in this article are included in the article's Creative Commons licence, unless indicated otherwise in a credit line to the material. If material is not included in the article's Creative Commons licence and your intended use is not permitted by statutory regulation or exceeds the permitted use, you will need to obtain permission directly from the copyright holder. To view a copy of this licence, visit http://creativecommons.org/licenses/by/4.0/.

\section{References}

1. Bernstein RB. Simple laboratory method for producing enriched carbon-13. Science. 1957;126(3264):119-20. https://doi.org/10. 1126/science.126.3264.119.

2. Cohen JS, Horsley W, Sternlicht H. The isolation of carbon-13 enriched amino acids. Biochim Biophys Acta. 1970;222(2):521-3. https://doi.org/10.1016/0304-4165(70)90144-3.

3. Ong SE, Blagoev B, Kratchmarova I, Kristensen DB, Steen H, Pandey A, Mann M. Stable isotope labeling by amino acids in cell culture, SILAC, as a simple and accurate approach to expression proteomics. Mol Cell Proteomics. 2002;1(5):376-86. https://doi. org/10.1074/mcp.m200025-mcp200.

4. Chong C, Muller M, Pak H, Harnett D, Huber F, Grun D, Leleu M, Auger A, Arnaud M, Stevenson BJ, Michaux J, Bilic I, Hirsekorn A, Calviello L, Simo-Riudalbas L, Planet E, Lubinski J, Bryskiewicz M, Wiznerowicz M, Xenarios I, Zhang L, Trono D, Harari A, Ohler U, Coukos G, Bassani-Sternberg M. Integrated proteogenomic deep sequencing and analytics accurately identify noncanonical peptides in tumor immunopeptidomes. Nat Commun. 2020;11(1):1293. https://doi.org/10.1038/s41467-020-14968-9.

5. Ebrahimi-Nik H, Michaux J, Corwin WL, Keller GL, Shcheglova T, Pak H, Coukos G, Baker BM, Mandoiu II, Bassani-Sternberg M, Srivastava PK. Mass spectrometry driven exploration reveals nuances of neoepitope-driven tumor rejection. JCI Insight. 2019;5(14). https://doi.org/10.1172/jci.insight.129152

6. Douglass J, Hsiue EH, Mog BJ, Hwang MS, DiNapoli SR, Pearlman AH, Miller MS, Wright KM, Azurmendi PA, Wang Q, Paul S, Schaefer A, Skora AD, Molin MD, Konig MF, Liu Q, Watson E, Li Y, Murphy MB, Pardoll DM, Bettegowda C, Papadopoulos N, Gabelli SB, Kinzler KW, Vogelstein B, Zhou S. Bispecific antibodies targeting mutant RAS neoantigens. Sci Immunol. 
2021;6(57):eabd5515. https://doi.org/10.1126/sciimmunol.abd55 15.

7. Villanueva J, Carrascal M, Abian J. Isotope dilution mass spectrometry for absolute quantification in proteomics: concepts and strategies. J Proteomics. 2014;96:184-99. https://doi.org/10. 1016/j.jprot.2013.11.004.

8. Whiteaker JR, Lin C, Kennedy J, Hou L, Trute M, Sokal I, Yan P, Schoenherr RM, Zhao L, Voytovich UJ, Kelly-Spratt KS, Krasnoselsky A, Gafken PR, Hogan JM, Jones LA, Wang P, Amon L, Chodosh LA, Nelson PS, McIntosh MW, Kemp CJ, Paulovich AG. A targeted proteomics-based pipeline for verification of biomarkers in plasma. Nat Biotechnol. 2011;29(7):625-34. https://doi.org/ 10.1038/nbt. 1900

9. Gerber SA, Rush J, Stemman O, Kirschner MW, Gygi SP. Absolute quantification of proteins and phosphoproteins from cell lysates by tandem MS. Proc Natl Acad Sci U S A. 2003;100(12):6940-5. https://doi.org/10.1073/pnas.0832254100.

10. Gallien S, Kim SY, Domon B. Large-scale targeted proteomics using internal standard triggered-parallel reaction monitoring (ISPRM). Mol Cell Proteomics. 2015;14(6):1630-44. https://doi.org/ 10.1074/mcp.O114.043968.

11. Bassani-Sternberg M, Braunlein E, Klar R, Engleitner T, Sinitcyn P, Audehm S, Straub M, Weber J, Slotta-Huspenina J, Specht K, Martignoni ME, Werner A, Hein R, Busch DH, Peschel C, Rad R, Cox J, Mann M, Krackhardt AM. Direct identification of clinically relevant neoepitopes presented on native human melanoma tissue by mass spectrometry. Nat Commun. 2016;7:13404. https://doi. org/10.1038/ncomms13404.

12. Chong C, Marino F, Pak H, Racle J, Daniel RT, Muller M, Gfeller D, Coukos G, Bassani-Sternberg M. High-throughput and sensitive immunopeptidomics platform reveals profound interferongamma-mediated remodeling of the human leukocyte antigen (HLA) ligandome. Mol Cell Proteomics. 2018;17(3):533-48. https://doi.org/10.1074/mcp.TIR117.000383.

13. R Core Team. R: a language and environment for statistical computing. 2021. Vienna, Austria. https://www.R-project.org/

14. Wickham H, Averick M, Bryan J, Chang W, McGowan L, François R, Grolemund G, Hayes A, Henry L, Hester J, Kuhn M, Pedersen T, Miller E, Bache S, Müller K, Ooms J, Robinson D, Seidel D, Spinu V, Takahashi K, Vaughan D, Wilke C, Woo K, Yutani H. Welcome to the Tidyverse. J Open Source Softw. 2019;4(43):1686. https://doi.org/10.21105/joss.01686.

15. Lacki MK, Valkenborg D, Startek MP. IsoSpec2: ultrafast fine structure calculator. Anal Chem. 2020;92(14):9472-5. https://doi. org/10.1021/acs.analchem.0c00959.

16. MacLean B, Tomazela DM, Shulman N, Chambers M, Finney GL, Frewen B, Kern R, Tabb DL, Liebler DC, MacCoss MJ. Skyline: an open source document editor for creating and analyzing targeted proteomics experiments. Bioinformatics. 2010;26(7):966-8. https://doi.org/10.1093/bioinformatics/btq054.

17. Toprak UH, Gillet LC, Maiolica A, Navarro P, Leitner A, Aebersold R. Conserved peptide fragmentation as a benchmarking tool for mass spectrometers and a discriminating feature for targeted proteomics. Mol Cell Proteomics. 2014;13(8):2056-71. https:// doi.org/10.1074/mcp.O113.036475.

18. Padfield D, Matheson G. nls.multstart: robust non-linear regression using AIC scores. 1.2.0 edn. 2020.

19. Stoppacher N, Josephs RD, Daireaux A, Choteau T, Westwood S, Wielgosz RI. Accurate quantification of impurities in pure peptide material-angiotensin I: comparison of calibration requirements and method performance characteristics of liquid chromatography coupled to hybrid tandem mass spectrometry and linear ion trap high-resolution mass spectrometry. Rapid Commun Mass Spectrom. 2015;29(18):1651-60. https://doi.org/10.1002/rcm.7261.

20. IUPAC. Matrix effect. In: Compendium of chemical terminology. 2020; https://doi.org/10.1351/goldbook.M03759

21. Trufelli H, Palma P, Famiglini G, Cappiello A. An overview of matrix effects in liquid chromatography-mass spectrometry. Mass Spectrom Rev. 2011;30(3):491-509. https://doi.org/10.1002/mas. 20298.

22. Zhou W, Yang S, Wang PG. Matrix effects and application of matrix effect factor. Bioanalysis. 2017;9(23):1839-44. https://doi. org/10.4155/bio-2017-0214.

23. Heller DN. Ruggedness testing of quantitative atmospheric pressure ionization mass spectrometry methods: the effect of coinjected matrix on matrix effects. Rapid Commun Mass Spectrom. 2007;21(5):644-52. https://doi.org/10.1002/rcm.2882.

24. Meier F, Geyer PE, Virreira Winter S, Cox J, Mann M. BoxCar acquisition method enables single-shot proteomics at a depth of 10,000 proteins in 100 minutes. Nat Methods. 2018;15(6):440-8. https://doi.org/10.1038/s41592-018-0003-5.

25. Virreira Winter S, Meier F, Wichmann C, Cox J, Mann M, Meissner F. EASI-tag enables accurate multiplexed and interference-free MS2-based proteome quantification. Nat Methods. 2018;15(7):52730. https://doi.org/10.1038/s41592-018-0037-8.

26. Wichmann C, Meier F, Virreira Winter S, Brunner AD, Cox J, Mann M. MaxQuant.Live enables global targeting of more than 25,000 peptides. Mol Cell Proteomics. 2019;18(5):982-94. https://doi.org/10.1074/mcp.TIR118.001131.

27. Salek M, Förster J, Köhler R, Riemer AB Poster \#820: detection of ultra-low abundant epitopes by targeted mass spectrometry. In: HUPO 2019, Adelaide, Australia. 2019.

28. Fritsche J, Kowalewski DJ, Backert L, Gwinner F, Dorner S, Priemer M, Tsou CC, Hoffgaard F, Romer M, Schuster H, Schoor O, Weinschenk T. Pitfalls in HLA ligandomics-how to catch a li(e) gand. Mol Cell Proteomics. 2021;20:100110. https://doi.org/10. 1016/j.mcpro.2021.100110.

29. Stopfer LE, Flower CT, Gajadhar AS, Patel B, Gallien S, LopezFerrer D, White FM. High-density, targeted monitoring of tyrosine phosphorylation reveals activated signaling networks in human tumors. Cancer Res. 2021;81(9):2495-509. https://doi.org/10. 1158/0008-5472.CAN-20-3804.

Publisher's note Springer Nature remains neutral with regard to jurisdictional claims in published maps and institutional affiliations. 